\title{
Спектры пленок SmS в дальней и средней ИК областях
}

\author{
( Ю.В. Улашкевич, В.В. Каминский, С.М. Соловьев, Н.В. Шаренкова \\ Физико-технический институт им. А.Ф. Иоффре Российской академии наук, \\ 194021 Санкт-Петербург, Россия \\ E-mail: vladimir.kaminski@mail.ioffe.ru
}

Поступила в Редакцию 20 мая 2019 г.

В окончательной редакции 28 мая 2019 г.

Принята к публикации 28 мая 2019 г.

Основные особенности зонной структуры, выявленные на объемных образцах, сохраняются в тонких поликристаллических пленках $\mathrm{SmS}$ : дно зоны проводимости образовано состояниями $s$-типа, на расстоянии 0.04-0.065 эВ от дна зоны проводимости в запрещенной зоне имеются примесные донорные уровни.

Ключевые слова: поликристаллические пленки сульфида самария, дальняя и средняя ИК области, зонная структура.

DOI: 10.21883/FTP.2019.11.48452.9163

\section{1. Введение}

Халькогениды самария используются в тензодатчиках, являются перспективными материалами для термопреобразователей и газоанализаторов [1-3]. Замена объемных материалов на тонкопленочные приводит к изменению их характеристик. Хотя исследования явлений переноса в тонкопленочных материалах на основе $\mathrm{SmS}$ ведутся давно, спектральных измерений этих материалов крайне мало. Нам известна лишь одна давняя работа [4], связанная с исследованиями пленок $\mathrm{SmS}$, однако она проведена в средней и высокочастотной ИК областях. В настоящей работе исследованы спектры поглощения в дальней и средней ИК областях пленок $\mathrm{SmS}$, нанесенных на прозрачные в данных областях подложки.

\section{2. Образы}

Поликристаллические пленки $\mathrm{SmS}$ толщиной 0.2-0.8 мкм были получены по известной методике [5] на тонких пластинках сапфира $(0.3 \mathrm{MM})$ или кремния $(0.5 \mathrm{MM})$. В первом случае существует область непрозрачности материала подложки $\left(330-1250 \mathrm{~cm}^{-1}\right)$, во втором - спектральные измерения можно проводить во всем исследуемом диапазоне, поскольку $\mathrm{Si}$ был достаточно чистым от посторонних примесей, чтобы не вносить искажения в проводимые измерения.

\section{3. Экспериментальная часть}

Спектры пропускания пленок и подложек в дальней ИК области (FIR) измерены при комнатной температуре с помощью ИК спектрометра IFS-113v фирмы Buker с разрешением $2 \mathrm{~cm}^{-1}$. Спектры пропускания этих же пленок и подложек в средней ИК области (MIR) измерены при комнатной температуре с помощью ИК спектрометра 1720X фирмы Perkin-Elmer с разрешением $4 \mathrm{~cm}^{-1}$. Для образцов проводилось несколько измерений, спектры усреднялись и „сшивались“ на общем краю диапазонов FIR и MIR. Коэффициент поглощения пленок $\mathrm{SmS}$ рассчитывался как натуральный логарифм пропускания образцов с учетом их толщины и фазового состава за вычетом поглощения их подложек.

Рентгеноструктурный анализ (РСА) образцов был проведен дифрактометрическим методом $(\theta-2 \theta$-сканирование) на рентгеновском дифрактометре ДРОН-2 в $K_{\alpha}$-излучении медного анода. Величина области когерентного рассеяния рентгеновского излучения (ОКР) определялась методом аппроксимации из величин истинного уширения пиков с индексами Миллера 200 и 111 по формуле Селякова-Шеррера [6]. Параметр кристаллической решетки, $a$, получен усреднением вычисленных значений в интервале углов $2 \theta$ от 90 до $160^{\circ} \mathrm{C}$.

Все структурные характеристики исследованных образцов приведены в таблице. Образцы 1 и 2 были

Параметры исследованных образцов

\begin{tabular}{|c|c|c|c|c|c|}
\hline № образца & \multicolumn{2}{|c|}{ Фазовый состав, \% } & ОКР, $\AA$ & $a, \AA$ & $d$, мкм \\
\hline 1 & $\begin{array}{l}\mathrm{SmS} \\
\mathrm{Sm}_{2} \mathrm{O}_{2} \mathrm{~S} \\
\mathrm{Sm}_{2} \mathrm{O}_{3}\end{array}$ & $\begin{array}{l}60 \\
\text { (следы) } \\
40\end{array}$ & 110 & 5.93 & 0.5 \\
\hline 2 & $\begin{array}{l}\mathrm{SmS} \\
\mathrm{Sm}_{2} \mathrm{O}_{2} \mathrm{~S} \\
, X^{* 6}\end{array}$ & $\begin{array}{r}80 \\
15 \\
5\end{array}$ & 70 & 5.926 & 0.20 \\
\hline 3 & $\begin{array}{l}\mathrm{SmS} \\
\mathrm{Sm}_{3} \mathrm{~S}_{4} \\
\mathrm{Sm}_{2} \mathrm{O}_{2} \mathrm{~S} \\
\mathrm{Sm}_{2} \mathrm{O}_{3}\end{array}$ & $\begin{array}{r}78 \\
6 \\
10 \\
6\end{array}$ & 130 & 5.94 & 0.74 \\
\hline 4 & $\begin{array}{l}\mathrm{SmS} \\
\mathrm{SmS} \text { met } \\
\mathrm{Sm}_{2} \mathrm{O}_{2} \mathrm{~S} \\
\mathrm{Sm}_{3} \mathrm{~S}_{4} \\
\mathrm{Sm}_{2} \mathrm{O}_{3} \\
\mathrm{Sm}_{2} \mathrm{~S}_{3}\end{array}$ & $\begin{array}{r}50 \\
10 \\
15 \\
8 \\
10 \\
7\end{array}$ & 127 & 5.948 & 0.79 \\
\hline
\end{tabular}

Примечание. * не идентифицированная примесь. 
приготовлены на кремниевых пластинках, 3 и $4-$ на сапфире.

Частотная зависимость коэффициента поглощения пленок $\mathrm{SmS}$ в области прозрачности сапфира получена усреднением по четырем исследованным образцам, в области непрозрачности - по двум образцам на кремниевых подложках. Вычисленная таким образом зависимость представлена на рис. 1. Можно видеть, что в длинноволновой области спектра наблюдается интенсивная полоса поглощения с частотой максимума при $179 \mathrm{~cm}^{-1}$, т. е. практически при том же значении, что и в спектрах отражения кристаллов и поликристаллических образцов [7,8]. Следовательно, эту полосу следует также отнести к фононному колебанию кристаллической решетки пленки.

В высокочастотной области спектра наблюдается монотонное возрастание коэффициента поглощения. Значения коэффициента поглощения при высоких частотах близки к величинам, полученным в более раннем исследовании [4], однако несколько превышают их. Это не является удивительным, поскольку в настоящей работе был исследован фазовый состав пленок. Обращает на себя внимание отсутствие пиков поглощения в области $1850 \mathrm{~cm}^{-1}$ - области $4 f$-уровней ионов самария $(\sim 0.23$ эВ). Это связано с тем, что $f-s$-переходы запрещены правилами отбора [9], а дно зоны проводимости в $\mathrm{SmS}$, согласно [10], образовано $s$-состояниями.

Наиболее интересным представляется поглощение в средней области спектра. Эта часть спектра наряду с областью FIR представлена на рис. 2. Поглощение в области 0.04-0.065 эВ обусловлено наличием примесных донорных уровней, определенных ранее из электрических измерений на объемных образцах $(0.045 \pm 0.015$ эВ) [11]. Эти уровни обязаны своим происхождением ионам $\mathrm{Sm}^{2+}$, находящимся не в регулярных узлах кристаллической решетки, а на границах ОКР.

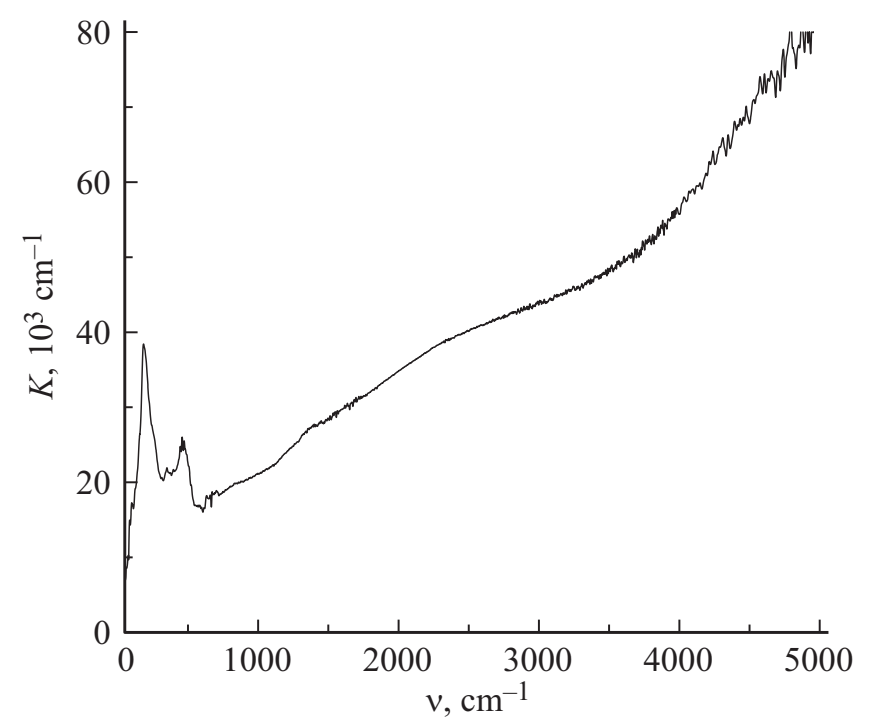

Рис. 1. Усредненная частотная зависимость коэффициента поглощения пленок $\mathrm{SmS}$

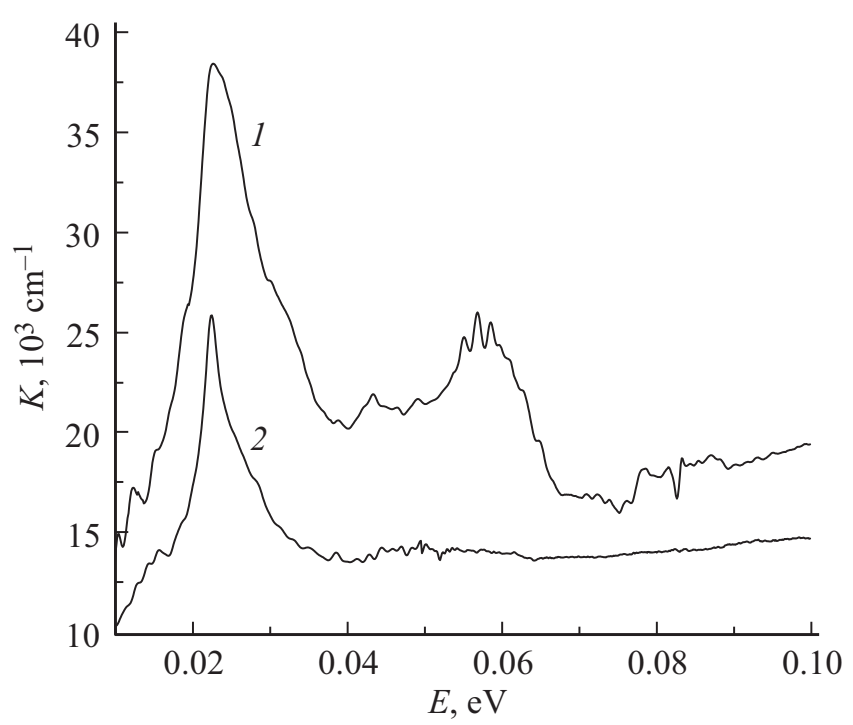

Рис. 2. 1 - спектр поглощения пленок $\mathrm{SmS} ; 2$ спектр поглощения, вычисленный с помощью преобразования Крамерса-Кронига из спектра отражения поликристалла $\mathrm{SmS}[12]$.

Наличие двух пиков можно объяснить тем, что в $\mathrm{SmS}$ дефектные ионы самария, ответственные за донорные уровни, могут располагаться в двух позициях: в междоузлиях и в вакансиях подрешетки серы [12]. Таким образом, в тонких поликристаллических пленках $\mathrm{SmS}$ имеется та же система примесных донорных уровней, что и в объемных образцах.

Интересно отметить, что преобразование КрамерсаКронига, примененное к измеренным ранее спектрам отражения поликристаллов $\mathrm{SmS}$ [13], также дает незначительное увеличение поглощения в той же области, что и пленки $\mathrm{SmS}$ (см. рис. 2). Меньшую величину этого поглощения в поликристаллах можно объяснить тем, что величина ОКР в них в несколько раз больше, чем в пленках, и соответственно концентрация донорных уровней меньше.

\section{4. Заключение}

Полученные данные по исследованию пленок подтверждают, что основные особенности зонной структуры, выявленные на объемных образцах, сохраняются и в тонких поликристаллических пленках $\mathrm{SmS}$ : дно зоны проводимости образовано состояниями $s$-типа, на расстоянии 0.04-0.065 эВ от дна зоны проводимости в запрещенной зоне имеются примесные донорные уровни.

\section{Конфликт интересов}

Авторы заявляют, что у них нет конфликта интересов. 


\section{Список литературы}

[1] В.В. Каминский, А.А. Молодых, С.М. Соловьев, А.А. Виноградов, Н.М. Володин. Патент РФ на изобретение № 2564698. Дата выдачи 09.09.2015. Бюл. № 28.

[2] В.М. Егоров, В.В. Каминский, М.М. Казанин, С.М. Соловьев, А.В. Голубков. Письма ЖТФ, 41, 50 (2015).

[3] С.А. Казаков, В.В. Каминский, С.М. Соловьев, Н.В. Шаренкова. Научное приборостроение, 25, 116 (2015).

[4] Л.Н. Глурджидзе, А.В. Гигинеишвили, Т.Л. Бжалава, 3.У. Джабуа, Т.А. Пагава, В.В. Самадзе, В.С. Оскотский. ФTТ, 20, 2727 (1978).

[5] Л.Н. Васильев, В.В. Каминский, Ю.М. Курапов, М.В. Романова, Н.В. Шаренкова. ФТТ, 38, 779 (1996).

[6] Ю.Д. Ягодкин, С.В. Добаткин. Завод. лаб. Диагностика матер., 73 (1), 38 (2007).

[7] V. Zelezny, J. Petzelt, V.V. Kaminski, M.V. Romanova, A.V. Golubkov. Sol. St. Commun., 72, 43 (1989).

[8] Ю.В. Улашкевич, В.В. Каминский, М.М. Казанин. ФТТ, 54, 2066 (2012).

[9] В.С. Оскотский, И.А. Смирнов. В сб.: Редкоземельные полупроводники (Л., Наука, 1977) с. 205.

[10] А.В. Голубков, Е.В. Гончарова, В.П. Жузе, Г.М. Логинов, В.М. Сергеева, И.А. Смирнов. Физические свойства халькогенидов редкоземельных элементов (Л., Наука, 1973).

[11] А.В. Голубков, Е.В. Гончарова, В.А. Капустин, М.В. Романова, И.А. Смирнов. ФТТ, 22, 3561, (1980).

[12] В.В. Каминский, А.В. Голубков, Л.Н. Васильев. ФТТ, 44, $1501(2002)$

[13] Ю.В. Улашкевич, В.В. Каминский, М.В. Романова, Н.В. Шаренкова. ФТП, 52, 184 (2018).

Редактор Г.А. Оганесян

\section{The far- and middle Infrared Spectra of SmS-film}

Y.V. Ulashkevich, V.V. Kaminski, S.M. Soloviev, N.V. Sharenkova

loffe Institute,

194021 St. Petersburg, Russia

Abstract The main features of the band structure found on bulk samples also remain in thin polycrystalline $\mathrm{SmS}$ films: the bottom of the conduction band is formed by $s$-type states, in the band gap there are impurity donor levels at a distance of $0.04-0.065 \mathrm{eV}$ from the bottom of the conduction band. 